\title{
Training Clarinet Players in Contemporary China
}

\author{
Changzhi Hou \\ Department of musical Upbringing and Education \\ Institute of Music, Theatre and Choreography \\ Herzen State Pedagogical University of Russia \\ Saint-Petersburg, Russia \\ E-mail: foreverzrj0917@gmail.com
}

\author{
Marina Chernaya \\ Department of musical Upbringing and Education \\ Institute of Music, Theatre and Choreography \\ Herzen State Pedagogical University of Russia \\ Saint-Petersburg, Russia
}

\begin{abstract}
This article is dedicated to studying the situation in Chinese clarinet pedagogy. The article"s authors, relying on the opinion of an authoritative Chinese clarinet teacher, are looking through the teaching appliances on playing the clarinet, which were published in China by the turn of the 20-21 centuries. They make a conclusion that there exist certain problems of supporting the educative process in China. The authors point out the absence of a national teaching technique in China and, finally, they state the problem and the need for creation of national methodic in the Chinese clarinet pedagogy.
\end{abstract}

Keywords-playing clarinet; teaching techniques in clarinet class; training appliances; schools of clarinet playing; national teaching techniques

\section{INTRODUCTION}

Music played on wind instruments takes a significant place in the modern musical culture. Learning to play wind instruments, and, in particular, playing the clarinet, is an essential component of modern musical performance culture, characterizing, inter alia, the processes taking place in the Chinese musical education. The processes associated with the improvement of clarinet teaching techniques, have affected many countries, including Russia and China.

In live teaching practice, a contradiction between the requirements to the level of formation of musical and performing skills of clarinet students and inadequacy of the theoretical and methodological support of the process has been developed, which determined relevance of the issue of this research and setting the problem of training professional clarinetists in China. The goal of this study is therefore determining the national peculiarities of training clarinet players in the Chinese educational institutions.

\section{INTER VIEW WITH A CHINESE TEACHER}

We asked the Chinese teaching specialist, who has worked for over 25 years at secondary schools and higher educational institutions, a few questions. He begged us not to mention his name, and promised to answer these professional questions as honestly as he could.

The text of the interview is given below.

A: What tutorials do you rely on?

B: I am using both Chinese and foreign didactic materials.

\section{A: What repertoire do you use?}

B: First of all, these are works of Carl Maria von Weber, composed for clarinet. They are: Concerto for clarinet and orchestra No. 1 f-moll op. 73, Concerto for clarinet and orchestra No. 2 op. 74, Concertino for clarinet and orchestra in c-moll / Es-dur op. 26, Variations for Clarinet and Piano on the theme from the Opera "Silvana" op. 33, Quintet for clarinet and string quartet B-dur op. 34, Grand Concerto Duo for clarinet and piano Es-dur op. 48. These works are very popular among students. I also use often such works as Gioachino Rossini's "Introduction, Theme and Variations" for clarinet and orchestra B-dur; Karol Kurpinsky's Concerto for clarinet and orchestra in the same key; in addition "Concerto for clarinet and brass band" Es-dur by N.A. Rimsky-Korsakov. Besides, I use fragments of opera music, in particular, the clarinet part in Verdi's opera "La Traviata".

A: What kind of difficulties do your students experience?

B: Improper breathing, lack of flexibility in the fingers, that is, they exhale too slowly, and their fingers are not nimble enough.

A: Which pedagogical clarinet teaching school do you pertain to?

B: There are no schools in Chinese clarinet playing. like?

A: What is the situation with clarinet playing in China

B: Playing the clarinet began in Europe at the end of the 17th century. In China, clarinet appeared only in the 19th century, hence clarinet teaching, clarinet studies in China have only a half-century history. Previously, the clarinet was taught only in higher musical institutions by a few teaching musicians, whereas now the art of clarinet playing is more and more developing and currently is being taught even in primary and secondary schools.

A: How well is the educational process supported by the methodological materials?

B: The most widely used are the following tutorials:

Tao Chun Xiao "Let's learn to play the clarinet"

Tao Chun Xiao "Learning to play the clarinet. Favorites" 
Ting Ledun "Fundamentals of clarinet playing".

The situation described by the authoritative teacher of clarinet playing seems to us rather alarming. Absence of a national school (to this problem he, in fact, tried to draw our attention) is, of course, due to the difference in cultures of the East and the West, late start of ontology of playing the clarinet in China, but at the same time, specifically it speaks for methodological failures in the field of Chinese clarinet pedagogy.

We decided to make a search on books on methodic of training clarinettists, issued in China by the turn of the 20-21 centuries. It will be nice to make a comparative analysis of the situation in Chinese and Russian clarinet education.

\section{Methodological SUPPORT OF TEACHING CLARINET PLAYING IN RUSSIA AND CHINA}

Comparing the situations with methodological support of the educational process in regard to teaching to play clarinet in Russia and China seems to us quite revealing. First of all, we admire the great scientific potential of the Russian methods, which, unfortunately, cannot be said about the Chinese approach where methodological efforts are clearly insufficient. The clarinet school in Russia was formed in the 19th century already and there was a long evolution in the educative process. For China the clarinet art is very young and unknown in many senses. Chinese authors in this field have so little experience. So, differences are being well seen.

\section{A. Methods in Learning Practice of Studying Clarinet in Russia}

Trying to characterize the main trends in Russian clarinet pedagogy, we turned to the theses defended not long ago and pointed out one work.

In 2010, Moscow clarinetist S. O. Suslov defended his thesis entitled "Formation of the national school of teaching to play clarinet as a problem of pedagogy of musical education".

The author, in particular, carries out comparative analysis of the two tutorials mostly common at the Russian professional educational institutions — "School of Playing the Clarinet" by S. V. Rozanov and "School of Playing the Clarinet of the French System" by V. V. Petrov. But this is not all, because S. O. Suslov identifies and analyzes a number of recently published in Russia textbooks and anthologies, the use of which could significantly enrich the studies and increase students' interest in the subject as well. They are: "Clarinetist's $A B C$ " by V. A. Getman; "Clarinetist's Musical Folder in Four Parts" from the series "Golden Library" (compiled and edited by V. N. Voronina); "School of Clarinet Studies in Four Notebooks" (compiled and edited by V. A. Sokolov); collection named "Masterpieces of Foreign Composers for Clarinet and Piano" (compiled by I. F. Olenchik). The author recommends for the use in teaching practice textbook "Methodic of teaching how to play wind instrument" by B. A. Dikov, published in 1983. Problems, pointed out by Dikov as actual in 80 -s, remain at the same status even now — ways of improving the initial stage of training young clarinetists, tight mastering of contemporary executive skills, creation of the optimal complex of everyday training for pupils and so on.

The author states that he had repeatedly attended master classes and lessons on playing the clarinet by the leading Russian teachers (V. A. Sokolov, V. V. Petrov, V. N. Voronina, I. P. Mozgovenko, A. A. Fedotov, E. A. Petrov, I. E. Butyrsky and others), which allowed him to carry out comparative analysis of attitudes and opinions of some prominent teachers on many issues to do with clarinet teaching technique [1]. One more thought is very important. Suslov is sure that the initial stage in studying playing the clarinet has a high value in the whole learning process. But there is no really complex methodic of teaching young clarinetists, even in Russia with its rich methodical traditions and big experience. So, he tries to point out methods of musical upbringing in clarinet classes of the leading teachers of playing the clarinet.

For example, Suslov gives in the thesis his analysis of method created by V. N. Voronina, who calls attention to the conducting the sound, search for discrete bowing in stroke technique, proper technology of the work with breathing, playing with the dynamic nuances and in different rhythmic combinations. Suslov points out similarities between Voronina"s method and method of studying scales practiced by I. E. Butyrsky, V. A. Sokolov and I. P. Mozgovenko (who uses different rhythmic variants as well). He names unique the original method of learning scales for everyday training worked on by V. V. Petrov, in which practicing without instrument is included.

The method of a mentally rehearsal seems very intricate. S. Suslov refers to the teaching practice of the prominent pianists - H. Neighaus. G. Kogan, K. Igumnov - and explains how this method can work at the class of clarinet.

The author points out the problem of learning etudes as wide-spread, compound and claiming attention of a Methodist. The practice in Children Musical Schools in Russia shows that a pupil is studying one etude in half a year and in any case executes the etude with failing. Leading Russian teachers of clarinet recommend to learn 4-6 etudes on different types of technical difficulties in half a year. This brings positive results and allows to grow up a real virtuoso.

The main goal of every executor is to form an artificial musical image, to expose the idea of a piece. The teacher helps young clarinetist in developing his analytical skills; together with a pupil he characterizes the piece, its mood, mode, its style peculiarities, its tonal plan. If such skills are formed from the beginning, then even during the second year of studying a pupil will be able to make such an analysis himself and be accustomed to make the executive analysis further on.

The experience of leading specialists, teaching clarinet, shows that it is very good to practice playing in ensemble, even during the first year of studying though the educative plan at the Children Musical School recommends it much later. 
There are several other active forms of studying musical material - sketchy playing of a piece, its transposition, reading the note text by sight, etc. All this active methods aim creation of optimal pedagogical conditions for forming necessary skills and abilities, to develop imaginary thinking at our lessons with young clarinetists.

The author points out that many valuable recommendations of great clarinetists, clarinet teachers and executors were not fixed in publications and are familiar only to the narrow circle of musicians. They generously shared their experience with their colleges and pupils during master-classes, open lessons, competitions, in private conversations as well.

In fact, many teaching clarinetists are able to create training appliances explaining a methodic of their own, but in the reality there are only singular books published long ago.

\section{B. Methods in Learning Practice of Studying Clarinet in China}

The authors of the article, in turn, inspired with Suslov" s thesis, undertook a study of clarinet playing tutorials, which were published in China at the turn of the 20-21 centuries, from the same perspective, i.e., analyzed which works were the most popular and which could enrich teaching lessons in clarinet class.

The list turned out to be discreet, totaling only about 30 items, some of which are not purely clarinet-dedicated literature, encompassing the art of playing on various wind instruments. Besides the works mentioned by the authorized teacher of playing the clarinet (see above), a number of encyclopedic reference books on clarinet playing, written both by a foreigner [2], and a Chinese author [3], were published in China.

It is noticeable that, in general, publishers tend to make the learning process enjoyable for students, thus translating into Chinese mostly those foreign books that would not be perceived as "boring" didactic material.

Clarinet classes may be diversified by some special editions, such as "Some Ideas on Clarinet Playing Exercises and Reed Technique" by Lee Khuashan (1991), "The Reed Technique in Playing the Clarinet" by Wang Zhensian, (1995), "Clarinet and Timbre" by Luy Zhengdong (1995), "The Experience of Learning to Play the Clarinet" by Wang Duanwey (1982).

Here is the whole list of books in chronological order with the translation of their titles in English:

Van Zhizhen, Van Zhantsi. Clarinet. Musical instrument. Beijing, 1979.

$\mathrm{Gu}$ Lyanli. History of evolution of Clarinet. Beijing: Musical art, 1981.

Lee Khuashan. History of the evolution of Clarinet. Ziluss Art, 1987.
Thaj Zunxyao. Teaching the clarinet playing. Beijing. The Newspaper of the Central Chinewse Conservatoire, 1987.

Lee Khuashan. Some questions on exercises to study playing the clarinet and uvular technique. Ziluss Publishing House, 1991.

Thao Chunsyao. Collection of pieces to study playing the clarinet. Beijing: People”s Musical Press, 1991.

Wang Duanwey. Essay on studying the clarinet. Symphony, 1993.

Thao Yabin. About the history of musical and cultural interactions between China and the West. Beijing: Chinese Publishing House of Encyclopedias, 1994.

Van Zhanxyan. Uvular technique in playing the clarinet. Nankin: The newspaper of the Nankin Art Institute, 1995.

Lyui Zhengdong. Clarinet and Timbre. Ziluss: Ziluss Art, 1995.

Zhi Zhen. About teaching playing the clarinet. Teaching art. 1996.

Xin Xyuizhi. Collection of articles on studying clarinet. Chengdu: Sichuăn Publishing House, 1998.

Zhen Zyankhua. About the wind instruments. Shanghai: Shanghai Publishing House, 1999.

Tao Chun Xiao Let's learn to play the clarinet. Tunxin Publishing House, 1999.

Wan Yuikhe. A new history of evolution of the Chinese music. Beijing: People"s Musical Press, 2002.

Juan U. Training appliance for dilettantes of how to play the clarinet. Beijing: People's Musical Press, 2002.

Chi Zhen. Training appliance for the beginners on playing the clarinet. Beijing: People's Musical Press, 2004.

Juan Fei. About some important questions on playing the clarinet. Beijing: Musical World, 2007.

Khost Rap. Merry schooling how to play the clarinet. Shanghai: Shanghai Musical Press, 2007.

Wan Zhensyan, Zhen Tsyankhua. General knowledge on evolution of clarinet art in China in the second half of the $20^{\text {th }}$ century. Nankin: Nankin Art Press, 2007.

C. Rawson / tr. by Juan Bin. Clarinet. Musical instrument. Beijing, 2007.

Ma Nee. About the exercises and learning the clarinet playing. Beijing: Musical World, 2008.

Wan Zhisin. About the evolution of clarinet and clarinet art. Forum of scientific-technical consultations. Beijing, 2009.

Tsui Khua, Juan Su. About training the pupils in learning how to play the clarinet. Comments on art. Beijing, 2010.

Dee Xyaoyan. The western art for China and traditional Chinese musical art. Chengdu: The newspaper Meyui, 2011. 
Zhan Zyafan. About evolution of clarinet art and the popularity of the instrument in China. Chunven: Chunven World, 2012.

Gho Khua. Considerations on the Chinese pieces for clarinet. Beijing: Musical forum, 2012.

However, these works are very few as yet. The fact, that they have been created by Chinese authors, is encouraging and it inspires the hope, that the potential of teaching techniques, accumulated in the methodic of teaching clarinet playing in China, will unveil to a fuller extent in the future. The task of creating the national methodic is actual now.

\section{Modelling the Main PRINCIPLES OF A Methodic of TEACHING How TO PLAY THE CLARINET ON THE INITIAL STAGE}

Let us return to Suslov"s thesis with its rich content. The author proposes the general principles to plan the lessons with the beginners of young age. He considers:

- any type of training activity at the lesson must not take much time, the tasks have to change each other quickly, and the teacher is to lead tactful guidance taking into account the pupil"s reaction;

- $\quad$ after the tasks demanding mental tension it is better to switch on more light types of work on learning and giving a possibility of emotional relaxation for the pupils must not be exhausted;

- try to use emotional "crescendo", i.e., in every 2-5 not only to change the type of activity but new types of action must be added, stimulating development of imaginary thinking giving the room for the creativity of the pupils. A lesson must be stopped at the pick of the emotional upraise and children will be waiting with desire and interest the next lesson [1].

The methodic must include professional trends in the teaching process and take into account the necessity of solving such problems as organization of the executive apparatus, breathing, ambusher, functions and role of the tongue, technique development.

A pupil must understand even on the early stage of studying that it is very important to develop moving abilities of his fingers because the clarinet is a virtuoso instrument. One of the bright forms of work to develop virtuosity and imaginary thinking of a pupil is listening to music. The modern system of training must include lists of pieces recommended for listening by a pupil.

From the very initial lessons it is very important to work on clarinet sound, its quality, as a one of the means of expressiveness. A teacher has to include in the everyday exercises of a beginner the sustained sounds in different nuances. Complexes of exercises must be compiled for different stages of training.

\section{CONCLUSION}

The situation with training clarinetists in China is far from being unambiguous.

On the one hand, zest in clarinet playing art is growing, which is manifested in the processes occurring in the Chinese teaching practice. In particular, training clarinet players in China is no longer a privilege of a few higher educational institutions, but is introduced at lower education levels.

On the other hand, the methodological support for educational process clearly falls short of the demand created in the Chinese society. For example, by the turn of the 20-21 centuries, there were only a few original methodological publications with a limited range of problems, which, however, can be considered just the beginning of the movement towards establishing national school of playing the clarinet and original training techniques.

\section{REFERENCES}

[1] Suslov S.O. Formation of the national school of learning to play the clarinet as a problem of pedagogy of musical education: Abstract of Ph.D. thesis: 13.00.02. Moscow, 2010. 22 p. [Suslov S. O. Formirovaniye natsionalnoi shkoly igry na klarnete kak problema musykalnogo obrazovaniya: Avtoreferat dis... kand. ped. nauk: 13.00.02. Moskva, 2010. 22 s.].

[2] Collins Rosson. Clarinet / translated by Zhang Bin. Beijing: People's Musical Press, 2007. 269 p.

[3] Chi Zheng, Handbook for clarinet beginners. Beijing: People's Musical Press, 2004. 153 p.

[4] Library of abstracts and theses on pedagogy. [Electronic resource]. Access mode: http://nauka-pedagogika.com/pedagogika-13-0002/dissertaciya-stanovlenie-otechestvennoy-shkoly-obucheniya-igrena-klamete-kak-problema-pedagogiki-muzykalnogoobrazovani ya\#ixzz45RVd0yod. Access date: 10.04.2016.

[5] Clarinet. [Electronic resource]. Access mode: http://epub.cnki.net/kns/brief/default_result.aspx. Access date: 12.04. 2016. 